\title{
Sistem Pendukung Keputusan Pemilihan Apoteker Terbaik Pada PT Kimia Farma (Persero) Tbk Medan Menerapkan Metode Vikor
}

\author{
Ardi Kusuma, Garuda Ginting \\ Program Studi Teknik Informatika, STMIK Budi Darma, Medan, Indonesia \\ Email: ardikusuma72@gmail.com
}

\begin{abstract}
Abstrak-Apoteker adalah tenaga profesi yang memiliki dasar pendidikan serta keterampilan dibidang farmasi dan diberi wewenang serta tanggung jawab untuk melaksanakan pekerjaan kefarmasian. Pada industri farmasi baik yang telah beroperasi maupun yang akan didirikan, paling sedikit wajib memiliki 3 (tiga) apoteker warga negara Indonesia. Sistem Pendukung Keputusan (SPK) memiliki tujuan memberikan prediksi, menyediakan informasi serta mengarahkan pengguna informasi agar mampu melakukan pengambilan keputusan dengan lebih efektif. Aplikasi Sistem Pendukung Keputusan (SPK) menggunakan CBIS (Computer Based Information System) yang fleksibel, interaktif, dan dapat diadaptasi, yang dikembangkan untuk mendukung solusi atas masalah manajemen spesifik yang tidak terstruktur. Metode VIKOR digunakan untuk mengatasi permasalahan multikriteria System yang kompleks yang berfokus pada rangking dan seleksi dari sebuah alternatif. Prosedur yang diusulkan pertama menghitung solusi yang ideal dan negatif dengan mempertimbangkan kriteria dan bobot setiap alternatif, dan utilitas yang sesuai.
\end{abstract}

Kata Kunci: Apoteker, Terbaik, SPK, VIKOR.

\begin{abstract}
Pharmacists are professional workers who have basic education and skills in the field of pharmacy and are given the authority and responsibility to carry out pharmaceutical work. In the pharmaceutical industry, both those that have been operating and are about to be established, there must be at least 3 (three) Indonesian pharmacists. Decision Support System (SPK) has the aim of providing predictions, providing information and directing information users to be able to make decisions more effectively. Decision Support System (SPK) applications use a flexible, interactive and adaptable CBIS (Computer Based Information System) that was developed to support solutions to specific unstructured management problems. The VIKOR method is used to overcome the problem of complex multi-criteria systems that focus on ranking and selection of alternatives. The first proposed procedure calculates the ideal and negative solutions by considering the criteria and weights of each alternative, and the corresponding utility.
\end{abstract}

Keywords: Pharmacists, Best, SPK, VIKOR.

\section{PENDAHULUAN}

Sumber daya manusia merupakan bagian terpenting pada setiap perusahaan besar yang ada di Indonesia, sebuah perusahaan dapat berkembang dengan baik tentunya dipengaruhi oleh kualitas para pekerjanya yang meliputi outsourcing dan karyawan. Sebagai salah satu pabrik farmasi terbesar dikota medan PT. Kimia Farma (Persero) Tbk Medan tak hanya memiliki karyawan biasa saja, salah satu karyawan yang menjadi sorotan utama pada perusahaan tersebut adalah apoteker. Pada industri farmasi baik yang telah beroperasi maupun yang akan didirikan, paling sedikit wajib memiliki 3 (tiga) apoteker warga negara Indonesia. Ketiga apoteker ini berperan sebagai penanggung jawab pemastian mutu yaitu Quality Assurance (QA), pengawasan mutu Quality Control (QC), dan Produksi. Meskipun demikian, apoteker yang bekerja pada industri farmasi tidak terbatas hanya pada bagian itu saja. Apoteker juga umumnya dibutuhkan di berbagai posisi di perusahaan industri farmasi, seperti bagian registrasi, penelitian, pengembangan pemesanan, pengadaan ataupun marketing.

Dalam pemilihan apoteker terbaik, PT. Kimia Farma (Persero) Tbk Medan memiliki kualifikasi tersendiri dalam pemilihannya. Dengan adanya apoteker yang berkualitas pada PT. Kimia Farma (Persero) Tbk Medan diharapkan mampu untuk menjadikan perusahaan lebih baik lagi . Pemilihan apoteker pada PT. Kimia Farma (Persero) Tbk Medan, saat ini masih dilakukan dengan cara manual, dimana dalam pemilihan hanya menggunakan microsoft excel dan cara tersebut masih memiliki banyak kekurangan diantaranya kesalahan penginputan data apoteker. Dengan demikian PT. Kimia Farma (Persero) Tbk Medan memerlukan sebuah sistem pendukung keputusan yang nantinya dapat membantu dalam pengambilan keputusan.

Sistem pendukung keputusan merupakan sebuah sistem yang dapat digunakan untuk mengambil sebuah keputusan dengan alternatif terbaik[1]-[3]. Proses pemilihan apoteker terbaik pada PT. Kimia Farma (Persero) Tbk Medan, sangat membutuhkan sistem pendukung keputusan agar dapat membantu mengambil keputusan yang tepat dalam menentukan apoteker terbaik pada PT. Kimia Farma (Persero) Tbk Medan. Dalam sistem pendukung keputusan, ada beberapa metode yang dapat digunakan untuk menyelesaikan suatu permasalahan dalam mengambil suatu keputusan. Metode sederhana yang sering digunakan seperti Elimination and Choice Translation Reality (ELECTRE)[4]-[6], Preference Ranking Organization Method for Enrichment Evaluation (PROMETHEE) II [7]-[9], Simple Additive Weighting (SAW)[10], [11], Weighted Product (WP), Multi-Objective Optimization On The Basic Of Ratio Analysist (MOORA)[12]-[15] Ataupun VIse Kriterijumska Optimizacija IKompromisno Resenje (VIKOR)[16]. Dan masih banyak lagi metode yang berkembang saat ini yang dapat diterapkan pada suatu sistem pendukung keputusan.

VIKOR (VIseKriterijumska Optimizacija IKompromisno Resenje) adalah metode optimasi multikriteriayang digunakan dalam sistem yang kompleks. Metode ini berfokus pada perangkingan dan memilih 
dari satu set alternatif, dan menentukan solusi kompromi untuk masalah kriteria yang bertentangan, yang dapat membantu para pengambil keputusan untuk mencapai keputusan akhir. Disini solusi kompromi adalah solusi yang layak yang paling dekat dengan ideal[17]-[20].

Metode VIKOR merupakan suatu metode untuk memecahkan masalah keputusan dengan kriteria yang saling bertentangan dan tidak dapat dibandingkan. VIKOR memberi peringkat alternatif dan menentukan solusi yang disebut kompromi yang paling dekat dengan ideal[21]-[23].

\section{METODE PENELITIAN}

\subsection{Sistem Pendukung Keputusan}

Secara umum Sistem Pendukung Keputusan di definisikan sebagai sebuah sistem yang mampu memberikan kemampuan baik kemampuan pemecahan masalah maupun kemampuan pengkomunikasian untuk masalah semiterstruktur. Secara khusus Sistem Pendukung Keputusan didefinisikan sebagai sebuah sistem yang mendukung kerja seorang manajer maupun sekelompok manajer dalam memecahkan masalah semi-terstruktur dengan cara memberikan informasi ataupun usulan menuju pada keputusan tertentu[1], [3], [24].

\subsection{Apoteker}

Apoteker adalah tenaga profesi yang memiliki dasar pendidikan serta keterampilan dibidang farmasi dan diberi wewenang serta tanggung jawab untuk melaksanakan pekerjaan kefarmasian.

\subsection{Metode Vise Kriterijumska Optimazacija Kompromisno Resenje (VIKOR)}

VIKOR (Vise Kriterijumska Optimizacija I Kompromisno Resenje) adalah metode optimasi multi- kriteria yang digunakan dalam sistem yang kompleks. Metode ini berfokus pada perangkingan dan memilih dari satu set alternatif, dan menentukan solusi kompromi untuk masalah kriteria yang bertentangan, yang dapat membantu para pengambil keputusan untuk mencapai keputusan akhir. Di sini, solusi kompromi adalah solusi yang layak yang paling dekat dengan ideal, dan kompromi berarti perjanjian didirikan dengan saling konsesi [25]-[27].

Langkah-langkah yang digunakan dalam metode VIKOR[28], [29], sebagai berikut:

1. Normalisasi matrik dengan cara nilai terbaik dalam satu kriteria dikurangi dengan nilai data sampel i kriteria j, lalu dibagi dengan nilai terbaik dalam satu kriteria dikurangi dengan nilai terjelek dalam satu kriteria.

$$
R_{i j}=\frac{\left(\max \mathrm{x}_{\mathrm{ij}}-\mathrm{X}_{\mathrm{ij}}\right)}{\left(\max \mathrm{X}_{\mathrm{ij}}-\min \mathrm{X}_{\mathrm{ij}}\right)}
$$

Dimana :

$\mathrm{R}_{\mathrm{ij}} \quad$ : nilai normalisasi sampel $i$ kriteria $j$

$\mathrm{X}_{\mathrm{ij}} \quad$ : nilai data sampel $i$ kriteria $j$

$\operatorname{Max} X_{\mathrm{ij}} \quad$ : nilai terbaik dalam satu kriteria

Min $\mathrm{X}_{\mathrm{ij}} \quad$ : nilai terjelek dalam satu kriteria

i : alternatif

j : kriteria

2. Menghitung nilai Utility Measure (S) dan Regret Measure (R). menghitung utility measure dengan cara menjumlah hasil dari perkalian bobot dengan hasil normalisasi matrik, menghitung regret measure dengan cara mencari nilai maksimal dari perkalian bobot dengan hasil normalisasi.

$\mathrm{W}_{\mathrm{j}} * \mathrm{R}_{\mathrm{ij}}$

$S_{i}=\sum_{j=1}^{n} W_{j} * R_{i j}$

Dimana :

$\mathrm{W}_{j}$ : bobot kriteria

$\mathrm{R}_{i}=\max \left[\mathrm{w}_{\mathrm{j}} * \mathrm{R}_{\mathrm{ij}}\right]$

3. Menghitung indeks vikor dengan cara nilai $\mathrm{S}$ dikurangi nilai $\mathrm{S}$ terkecil lalu dibagi dengan nilai $\mathrm{S}$ terbesar dikurangi dengan nilai $\mathrm{S}$ terkecil dan dikali $\mathrm{v}$ dan dijumlahkan dengan nilai $\mathrm{R}$ dikurangi nilai $\mathrm{R}$ terkecil lali dibagi dengan nilai $\mathrm{R}$ terbesar dikurangi nilai $\mathrm{R}$ terkecil dan dikali dengan 1 dikurangi $\mathrm{v}$.

$Q_{i}=\frac{\left(S_{i}-S_{i} \min \right)}{\left(S_{i} \max -S_{i} \min \right)} * v+\frac{\left(R_{i}-R_{i} \min \right)}{\left(R_{i} \max -R_{i} \min \right)} *(1-v)$

Dimana :

$\begin{array}{ll}\mathrm{V} & : 0.5 \\ \mathrm{~S}_{\mathrm{i}} \min & : \text { nilai } \mathrm{S} \text { terkecil } \\ \mathrm{S}_{\mathrm{i}} \max & : \text { nilai } \mathrm{S} \text { terbesar } \\ \mathrm{R}_{\mathrm{i}} \min & : \text { nilai R terkecil }\end{array}$


$\mathrm{R}_{\mathrm{i}} \max \quad$ : nilai R terbesar

Sampel dengan nilai Q terkecil merupakan sampel terbaik.

4. Merangking Alternatif

Mengusulkan Solusi kompromi alternatif yang memiliki peringkat terbaik dengan mengukur indek Vikor yang minimum.

\section{HASIL DAN PEMBAHASAN}

Analisa merupakan langkah awal dalam penyelesaian dan mengidentifikasi sebuah permasalahan yang terjadi. Analisa masalah memiliki peranan penting dalam proses analisis untuk mencapai dan memperoleh hasil yang akurat dalam sebuah sistem. Pemilihan Apoteker terbaik pada PT. Kimia Farma (Persero) Tbk Medan merupakan pemilihan yang bukan didasarkan oleh kemauan seseorang, pemilihan ini didasari data yang ada dan diperoleh dari hasil kinerja apoteker tersebut. Dimana data tersebut terdiri dari beberapa alternatif-alternatif dan kriteria-kriteria yang tepat sebagai bahan pertimbangan untuk melakukan pemilihan apoteker terbaik. pemilhan ini dilakukan oleh suatu organisasi yang diberi nama Serikat Pekerja (SP), untuk pemilihan apoteker terbaik pada PT. Kimia Farma (Persero) Tbk Medan sebelumnya hanya menggunakan microsoft axcel dalam pemilihannya. Dengan penerapan sistem pendukung keputusan diharapkan dapat membantu menghasilkan alternatif yang tepat dan sesuai dengan kriteria yang telah ditentukan oleh PT. Kimia Farma (Persero) Tbk Medan.

1. Data Alternatif

Tabel 1. Data Alternatif

\begin{tabular}{cl}
\hline Alternatif (A) & \multicolumn{1}{c}{ Keterangan } \\
\hline $\mathrm{A}_{1}$ & Yurista Gilang Ikhtiarsyah S.Farm., Apt \\
$\mathrm{A}_{2}$ & Unggul Sujati S.Farm., Apt \\
$\mathrm{A}_{3}$ & Bram Hik Anugraha S.Farm., Apt \\
$\mathrm{A}_{4}$ & Rahmat Rasyidi S.Farm., Apt \\
$\mathrm{A}_{5}$ & Brata Jaya Laksana S.Farm., Apt \\
$\mathrm{A}_{6}$ & Andi Budi Prawoto S.Farm., Apt \\
\hline
\end{tabular}

2. Data Kriteria

Tabel 2. Data Kriteria

\begin{tabular}{cl}
\hline Kriteria (C) & \multicolumn{1}{c}{ Keterangan } \\
\hline $\mathrm{C}_{1}$ & Efisiensi Keuangan \\
$\mathrm{C}_{2}$ & Absensi \\
$\mathrm{C}_{3}$ & Masa Jabatan \\
$\mathrm{C}_{4}$ & Memiliki Keterampilan Teknis \\
$\mathrm{C}_{5}$ & Inovatif \\
\hline
\end{tabular}

3. Bobot

Tabel 3. Nilai Bobot

4. Rating Kecocokan

\begin{tabular}{ll}
\hline Range & Nilai \\
\hline Sangat buruk & 10 \\
Buruk & 20 \\
Cukup & 30 \\
Baik & 40 \\
Sangat baik & 50 \\
\hline
\end{tabular}

Tabel 4. Rating Yang Telah Dibobotkan

\begin{tabular}{lllllc}
\hline & \multicolumn{5}{c}{ Kriteria } \\
\cline { 2 - 6 } Alternatif & $\mathrm{C} 1$ & $\mathrm{C} 2$ & $\mathrm{C} 3$ & $\mathrm{C} 4$ & $\mathrm{C} 5$ \\
\hline $\mathrm{A}_{1}$ & 50 & 50 & 40 & 50 & 30 \\
$\mathrm{~A}_{2}$ & 50 & 40 & 20 & 50 & 50 \\
$\mathrm{~A}_{3}$ & 50 & 50 & 10 & 50 & 30 \\
$\mathrm{~A}_{4}$ & 40 & 20 & 30 & 50 & 30 \\
$\mathrm{~A}_{5}$ & 50 & 40 & 30 & 50 & 50 \\
$\mathrm{~A}_{6}$ & 40 & 10 & 20 & 30 & 50 \\
Max & $\mathbf{5 0}$ & $\mathbf{5 0}$ & $\mathbf{4 0}$ & $\mathbf{5 0}$ & $\mathbf{5 0}$ \\
Min & $\mathbf{4 0}$ & $\mathbf{1 0}$ & $\mathbf{1 0}$ & $\mathbf{3 0}$ & $\mathbf{3 0}$ \\
\hline
\end{tabular}

5. Penyelesaian dengan Metode VIKOR 
Dari tabel nilai masing-masing kriteria akan dilakukan normalisasi data,yaitu:

a. Melakukan normalisasi data

Alternatif untuk A1

$\mathrm{R}(\mathrm{A} 1), \mathrm{C} 1=\frac{(50-50)}{(50-40)}=\frac{0}{10}=0$
$\mathrm{R}(\mathrm{A} 1), \mathrm{C} 2=\frac{(50-50)}{(50-10)}=\frac{0}{40}=0$
$\mathrm{R}(\mathrm{A} 1), \mathrm{C} 3=\frac{(40-40)}{(40-10)}=\frac{0}{30}=0$
$\mathrm{R}(\mathrm{A} 1), \mathrm{C} 4=\frac{(50-50)}{(50-30)}=\frac{0}{20}=0$
$\mathrm{R}(\mathrm{A} 1), \mathrm{C} 5=\frac{(50-30)}{(50-30)}=\frac{20}{20}=1$

Alternatif untuk A2

$\mathrm{R}(\mathrm{A} 2), \mathrm{C} 1=\frac{(50-50)}{(50-40)}=\frac{0}{10}=0$

$\mathrm{R}(\mathrm{A} 2), \mathrm{C} 2=\frac{(50-40)}{(50-10)}=\frac{10}{40}=0.25$

$\mathrm{R}(\mathrm{A} 2), \mathrm{C} 3=\frac{(40-20)}{(40-10)}=\frac{20}{30}=0.66$

$\mathrm{R}(\mathrm{A} 2), \mathrm{C} 4=\frac{(50-50)}{(50-30)}=\frac{0}{20}=0$

$\mathrm{R}(\mathrm{A} 2), \mathrm{C} 5=\frac{(50-50)}{(50-30)}=\frac{0}{20}=0$

Dengan langkah-langkah perhitungan diatas maka di dapat data normalisasi semua sample, berikut disajikan tabel data normalisasi semua sample (normalisasi matriks).

Tabel 5. Hasil Normalisasi Matriks

\begin{tabular}{cccccc}
\hline & \multicolumn{5}{c}{ Kriteria } \\
\cline { 2 - 6 } Alternatif & $\mathrm{C} 1$ & $\mathrm{C} 2$ & $\mathrm{C} 3$ & $\mathrm{C} 4$ & $\mathrm{C} 5$ \\
\hline $\mathrm{A}_{1}$ & 0 & 0 & 0 & 0 & 1 \\
$\mathrm{~A}_{2}$ & 0 & 0.25 & 0.66 & 0 & 0 \\
$\mathrm{~A}_{3}$ & 0 & 0 & 1 & 0 & 1 \\
$\mathrm{~A}_{4}$ & 1 & 0.75 & 0.33 & 0 & 1 \\
$\mathrm{~A}_{5}$ & 0 & 0.25 & 0.33 & 0 & 0 \\
$\mathrm{~A}_{6}$ & 1 & 1 & 0.66 & 1 & 0 \\
\hline
\end{tabular}

Tabel 6. Normalisasi X Bobot

\begin{tabular}{llllll}
\hline & \multicolumn{5}{c}{ Kriteria } \\
\cline { 2 - 6 } Alternatif & \multicolumn{1}{c}{$\mathrm{C} 1$} & \multicolumn{1}{c}{$\mathrm{C} 2$} & \multicolumn{1}{c}{$\mathrm{C} 3$} & \multicolumn{1}{c}{$\mathrm{C} 4$} & \multicolumn{1}{c}{$\mathrm{C} 5$} \\
\hline $\mathrm{A}_{1}$ & $0 * 0.3$ & $0 * 0.15$ & $0 * 0.1$ & $0 * 0.25$ & $1 * 0.2$ \\
$\mathrm{~A}_{2}$ & $0 * 0.3$ & $0.25 * 0.15$ & $0.66 * 0.1$ & $0 * 0.25$ & $0 * 0.2$ \\
$\mathrm{~A}_{3}$ & $0 * 0.3$ & $0 * 0.15$ & $1 * 0.1$ & $0 * 0.25$ & $1 * 0.2$ \\
$\mathrm{~A}_{4}$ & $1 * 0.3$ & $0.75 * 0.15$ & $0.33 * 0.1$ & $0 * 0.25$ & $1 * 0.2$ \\
$\mathrm{~A}_{5}$ & $0 * 0.3$ & $0.25 * 0.15$ & $0.33 * 0.1$ & $0 * 0.25$ & $0 * 0.2$ \\
$\mathrm{~A}_{6}$ & $1 * 0.3$ & $1 * 0.15$ & $0.66 * 0.1$ & $1 * 0.25$ & $0 * 0.2$ \\
\hline
\end{tabular}

Tabel 7. Normalisasi X Bobot Kriteria

\begin{tabular}{cccccc}
\hline & \multicolumn{5}{c}{ Kriteria } \\
\cline { 2 - 6 } Alternatif & $\mathrm{C} 1$ & $\mathrm{C} 2$ & $\mathrm{C} 3$ & $\mathrm{C} 4$ & $\mathrm{C} 5$ \\
\hline $\mathrm{A}_{1}$ & 0 & 0 & 0 & 0 & 0.2 \\
$\mathrm{~A}_{2}$ & 0 & 0.0375 & 0.066 & 0 & 0 \\
$\mathrm{~A}_{3}$ & 0 & 0 & 0.1 & 0 & 0.2 \\
$\mathrm{~A}_{4}$ & 0.3 & 0.1125 & 0.033 & 0 & 0.2 \\
$\mathrm{~A}_{5}$ & 0 & 0.0375 & 0.033 & 0 & 0 \\
$\mathrm{~A}_{6}$ & 0.3 & 0.15 & 0.066 & 0.25 & 0 \\
\hline
\end{tabular}

b. Menghitung Nilai $\mathrm{S}$ dan $\mathrm{R}$

Rumus $\mathrm{S}_{\mathrm{i}}=\sum_{j=1}^{n}$ wj $x(R i j)$

$\mathrm{wj}=$ bobot kriteria

Nilai S didapatkan dari penjumlahan hasil perkalian bobot kriteria dengan data pada setiap sample.

S (A1) $\quad=0+0+0+0+0,2$

$=0.2$ 


$$
\begin{array}{ll}
\mathbf{S}(\mathbf{A 2}) & =0+0.0375+0.066+0+0 \\
& =0.1035 \\
\mathbf{S}(\mathbf{A 3}) & =0+0+0.1+0+0.2 \\
& =0.3 \\
\mathbf{S}(\mathbf{A 4}) \quad & =0.3+0.1125+0.033+0+0,2 \\
& =0.6455 \\
\mathbf{S}(\mathbf{A 5}) \quad & =0+0.0375+0.033+0+0 \\
\mathbf{S}(\mathbf{A 6}) & =0.0705 \\
& =0.3+0.15+0.066+0.25+0 \\
& =0.766
\end{array}
$$

Rumus $\mathrm{R} i=\operatorname{Max} j[\mathrm{w} j \mathrm{x} \operatorname{R} i j]$

Nilai R adalah nilai terbesar dari perkalian bobot kriteria dengan data normalisasi dari setiap alternatif.

$$
\begin{array}{ll}
\mathrm{R}(\mathrm{A} 1) & =0,2 \\
\mathrm{R}(\mathrm{A} 2) & =0.066 \\
\mathrm{R}(\mathrm{A} 3) & =0.2 \\
\mathrm{R}(\mathrm{A} 4) & =0.3 \\
\mathrm{R}(\mathrm{A} 5) & =0.0375 \\
\mathrm{R}(\mathrm{A} 6) & =0.3
\end{array}
$$

Tabel 8. Nilai S dan R

\begin{tabular}{cll}
\hline Alternatif & Nilai S & Nilai R \\
\hline $\mathrm{A}_{1}$ & 0.2 & 0.2 \\
$\mathrm{~A}_{2}$ & 0.1035 & 0.066 \\
$\mathrm{~A}_{3}$ & 0.3 & 0.2 \\
$\mathrm{~A}_{4}$ & 0.6455 & $\mathbf{0 . 3}$ \\
$\mathrm{A}_{5}$ & $\mathbf{0 . 0 7 0 5}$ & $\mathbf{0 . 0 3 7 5}$ \\
$\mathrm{A}_{6}$ & $\mathbf{0 . 7 6 6}$ & $\mathbf{0 . 3}$ \\
\hline
\end{tabular}

Pada tabel diatas, terdapat nilai data yang dipertebal atau ditandai. Keduan data tersebut masing-masing adalah nilai terbesar dan terkecil dari nilai $\mathrm{S}$ dan $\mathrm{R}$.

c. Menghitung indeks

Rumus $\mathrm{Q}_{\mathrm{i}}=\left[\frac{S_{i}-S^{+}}{S^{-}-S^{+}}\right] \mathrm{v}+\left[\frac{R_{i}-R^{+}}{R^{-}-R^{+}}\right](1-\mathrm{v})$

Keterangan :

$\mathbf{S}^{-}=$nilai $\mathrm{S}$ terbesar $\mathbf{R}^{-}=$nilai $\mathrm{R}$ terbesar

$\mathbf{S}^{+}=$nilai $\mathrm{S}$ terkecil $\mathbf{R}^{+}=$nili $\mathbf{R}$ terkecil

Alternatif dengan nilai Q terkecil merupakan alternatif terbaik. Berikut perhitungan nilai indeks Vikor (Q):

$$
\begin{aligned}
\mathrm{Q}(\mathrm{A1}) & =\left[\frac{0.2-0.0705}{0.766-0.0705}\right] * 0.5+\left[\frac{0.2-0.0375}{0.3-0.0375}\right] *(1-0.5) \\
& =\left[\frac{0.1295}{0.6955}\right] * 0.5+\left[\frac{0.1625}{0.2625}\right] *(0.5) \\
& =(0.1861 * 0.5)+(0.6190 * 0.5) \\
& =0.0930+0.3095=0.4025 \\
\mathrm{Q}(\mathbf{A 2}) & =\left[\frac{0.1035-0.0705}{0.766-0.0705}\right] * 0.5+\left[\frac{0.066-0.0375}{0.3-0.0375}\right] *(1-0.5) \\
& =\left[\frac{0.033}{0.6955}\right] * 0.5+\left[\frac{0.0285}{0.2625}\right] *(0.5) \\
& =(0.047 * 0.5)+(0.10857 * 0.5) \\
& =0.0235+0.0543=0.0778
\end{aligned}
$$

Tahapan selanjutnya setelah melakukan perhitungan indeks Vikor (Q) diatasadalah melakukan perangkingan berdasarkan nilai Vikor (Q) paling kecil.

Tabel 9. Perangkingan Indeks Vikor

\begin{tabular}{ccc}
\hline Peringkat & Apoteker & Nilai Q \\
\hline 1 & $\mathrm{~A}_{5}$ & 0 \\
2 & $\mathrm{~A}_{2}$ & 0.0778 \\
3 & $\mathrm{~A}_{1}$ & 0.4025 \\
4 & $\mathrm{~A}_{3}$ & 0.4745 \\
5 & $\mathrm{~A}_{4}$ & 0.91335 \\
6 & $\mathrm{~A}_{6}$ & 1 \\
\hline
\end{tabular}

Dari tabel diatas diperoleh data bahwa sampel (A5) yaitu Brata Jaya Laksana S.Farm., Aptyang memiliki nilai indeks Vikor terkecil yaitu 0, sehingga dalam penelitian ini sampel Apoteker yang bernama Brata Jaya Laksana S.Farm., Apt (A5) menempati peringkat pertama dalam Perangkingan Menggunakan Metode Vikor. 


\section{KESIMPULAN}

Berdasarkan pembahasan dari penelitian mengenai pemilihan apoteker terbaik pada PT. Kimia Farma (Persero) Tbk Medan Menerapkan Metode VIKOR, maka diperoleh kesimpulan sebagai berikut:

1. Metode VIKOR dapat ditentukan urutan prioritas dalam perhitungan multikriteria.

2. Penerapan kriteria Efisiensi Keuangan, Absensi, Masa Jabatan, Memiliki Keterampilan Teknis, dan Inovatif. dapat membantu dalam pemilihan apoteker terbaik pada PT. Kimia Farma (Persero) Tbk Medan.

\section{REFERENCES}

[1] T. Limbong et al., Sistem Pendukung Keputusan: Metode \& Implementasi. Medan: Yayasan Kita Menulis, 2020.

[2] S. Kusumadewi, S. Hartati, A. Harjoko, and Retantyo Wardoyo, Fuzzy Multi-Attribute Decision Making (FUZZY MADM). 2006

[3] Kusrini, Konsep dan Aplikasi Sistem Pendukung Keputusan. 2007.

[4] I. Saputra, S. I. Sari, and Mesran, "PENERAPAN ELIMINATION AND CHOICE TRANSLATION REALITY ( ELECTRE ) DALAM PENENTUAN KULKAS TERBAIK,” KOMIK (Konferensi Nas. Teknol. Inf. dan Komputer), vol. I, pp. $295-305,2017$.

[5] M. Mesran, R. Rusiana, and M. Sianturi, "Decision Support System for Termination of Employment using Elimination and Choice Translation Reality Method," J. Teknol. dan Sist. Komput., vol. 6, no. 4, p. 135, 2018.

[6] L. N. Zulita, "Penerapan Metode ELECTRE Dalam Pengambilan Keputusan Pemilihan Produk Unggulan Daerah,” J. Inf. Sist. Res., vol. 1, no. 3, pp. 162-167, 2020.

[7] A. S. Harahap, T. Tulus, and E. Budhiarti, "PENERAPAN METODE ENTROPY DAN METODE PROMETHEE DALAM MERANGKING KUALITAS GETAH KARET,” Pelita Inform. Inf. dan Inform., vol. 16, no. 3, Jul. 2017.

[8] D. Assrani, Mesran, R. D. Sianturi, Yuhandri, and A. Iskandar, "SISTEM PENDUKUNG KEPUTUSAN PEMILIHAN GURU PRODUKTIF PESERTA PELATIHAN ASESOR KOMPETENSI LSP P1 SMK SWASTA DWIWARNA MEDAN MENGGUNAKAN METODE THE EXTENDED PROMETHEE II (EXPROM II) | Assrani | KOMIK (Konferensi Nasional Teknologi Informasi dan Komputer)," in KOMIK (Konferensi Nasional Teknologi Informasi dan Komputer), 2018, vol. 2 , no. 1.

[9] M. Mesran, P. Pristiwanto, and I. Sinaga, "Implementasi Promethee II Dalam Pemilihan Pestisida Terbaik Untuk Perawatan Daun Pada Tanaman Cabe," CESS (Journal Comput. Eng. Syst. Sci., vol. 3, no. 2, pp. 46-53, 2018.

[10] S. H. Sahir, R. Rosmawati, and K. Minan, "Simple Additive Weighting Method to Determining Employee Salary Increase Rate," Int. J. Sci. Res. Sci. Technol., vol. 3, no. 8, pp. 42-48, 2017.

[11] Khairul;, M. Simaremare, A. Putera, and U. Siahaan, "Decision Support System in Selecting The Appropriate Laptop Using Simple Additive Weighting," Int. J. Recent TRENDS Eng. Res., vol. 2, no. 12, pp. 215-222, 2016.

[12] S. Sutarno, M. Mesran, S. Supriyanto, Y. Yuliana, and A. Dewi, "Implementation of Multi-Objective Optimazation on the Base of Ratio Analysis (MOORA) in Improving Support for Decision on Sales Location Determination,” in 2nd International Conference on Advance \& Scientific Innovation, 2019, vol. 1424, no. 1.

[13] Mesran, R. K. Hondro, M. Syahrizal, A. P. U. Siahaan, R. Rahim, and Suginam, "Student Admission Assessment using Multi-Objective Optimization on the Basis of Ratio Analysis (MOORA)," J. Online Jar. COT POLIPT, vol. 10, no. 7, pp. 1-6, 2017.

[14] N. W. Al-Hafiz, Mesran, and Suginam, "Sistem Pendukung Keputusan Penentukan Kredit Pemilikan Rumah Menerapkan MultiObjective Optimization on the Basis of Ratio Analysis ( Moora )," KOMIK (Konferensi Nas. Teknol. Inf. dan Komputer), vol. I, no. 1 , pp. 306-309, 2017.

[15] S. Dedi, A. Pardede, A. Harahap, A. Putera, and U. Siahaan, "Sistem Pendukung Keputusan Pemilihan Peserta Jaminan Kesehatan Masyarakat ( Jamkesmas ) Menerapkan Metode MOORA," vol. 2, no. 2, pp. 16-22, 2018

[16] Y. J. B. Parrangan et al., "The Implementation of VIKOR method to Improve the Effectiveness of Sidi learning Graduation," Int. $J$. Eng. Technol., vol. 7, no. 3.4 Special Issue 4, 2018.

[17] Y. Kristyawan and A. Rizeki, "Sistem Pendukung Keputusan Distribusi Rehabilitas Sosial Rumah Tidak Layak Huni pada Kab Sampang Menggunakan Metode Vikor," vol. 2, no. 1, pp. 1-8, 2017.

[18] N. Sutrikanti, H. Situmorang, Fachrurrazi, H. Nurdiyanto, and M. Mesran, "Implementasi Pendukung Keputusan Dalam Pemilihan Calon Peserta Cerdas Cermat Tingkat SMA Menerapkan Metode VIKOR,” J. Ris. Komput. (JURIKOM, vol. 5, no. 2407-389X, pp. 109-113, 2018.

[19] A. Siregar, P. Ginting, M. Mesran, and L. T. Sianturi, "Implementasi Metode Vikor Dalam Pemilihan Supplier Bahan Baku," KOMIK (Konferensi Nas. Teknol. Inf. dan Komputer), vol. I, pp. 132-138, 2017.

[20] I. Wijaya and Mesran, "Penerapan Metode AHP dan VIKOR Dalam Pemilihan Karyawan Berprestasi," in Seminar Nasional Teknologi Komputer \& Sains (SAINTEKS), 2019, pp. 301-309.

[21] T. Imandasari and A. P. Windarto, "Penerapan Metode VIKOR Pada Pemilihan Popok Bayi Berdasarkan Jenis Kulit," pp. 215-220, 2018 .

[22] M. Mesran et al., "The VIKOR Method to Support the Effectiveness of Decisions in Determining Work Incentive Recipients," J. Phys. Conf. Ser., vol. 1175, p. 012043, 2019.

[23] N. Sutrikanti, H. Situmorang, F. Fachrurrazi, H. Nurdiyanto, and M. Mesran, "Implementasi Pendukung Keputusan Dalam Pemilihan Calon Peserta Cerdas Cermat Tingkat SMA Menerapkan Metode VIKOR,” JURIKOM (Jurnal Ris. Komputer), vol. 5, no. 2, pp. 109113, Apr. 2018.

[24] T.-P. Turban, E., Aronson, J., \& Liang, Decision Support Systems And Inteligence System. US: Prentice-Hall, 2005.

[25] M. Yazdani and F. R. Graeml, "VIKOR and its Applications," Int. J. Strateg. Decis. Sci., vol. 5, no. 2, pp. 56-83, Apr. 2014

[26] G.-H. Tzeng and J.-J. Huang, Multiple Attribute Decision Making Method And Applications. CRC Press, 2011.

[27] M. Sianturi, S. Wulan, Suginam, Rohminatin, and Mesran, "Implementasi Metode VIKOR Untuk Menentukan Bahan Kulit Terbaik Dalam Pembuatan Ikat Pinggang," J. Ris. Komput., vol. 5, no. 1, pp. 56-60, 2018.

[28] A. Mardani, E. Zavadskas, K. Govindan, A. Amat Senin, and A. Jusoh, "VIKOR Technique: A Systematic Review of the State of the Art Literature on Methodologies and Applications," Sustainability, vol. 8, no. 1, p. 37, Jan. 2016

[29] A. A. Trisnani, D. U. Anwar, W. Ramadhani, M. M. Manurung, and A. P. U. Siahaan, "Sistem Pendukung Keputusan Pemilihan Karyawan Berprestasi Menerapkan Metode Vise Kriterijumska Optimizajica I Kompromisno Resenje (VIKOR)," JURIKOM (Jurnal Ris. Komputer), vol. 5, no. 2, pp. 85-90, Apr. 2018 